\title{
Portavoces oficiales y estrategia audiovisual en la crisis de la Covid-19 en España
}

\section{Official spokespersons and audiovisual strategy in the Covid-19 crisis in Spain}

\author{
José-Vicente García-Santamaría; María-José Pérez-Serrano; Miriam Rodríguez-Pallares
}

Cómo citar este artículo:

García-Santamaría, José-Vicente; Pérez-Serrano, María-José; Rodríguez-Pallares, Miriam (2020). “Portavoces oficiales y estrategia audiovisual en la crisis de la Covid-19 en España”. Profesional de la información, v. 29, n. 5, e290513.

https://doi.org/10.3145/epi.2020.sep.13

Artículo recibido el 25-05-2020 Aceptación definitiva: 17-06-2020

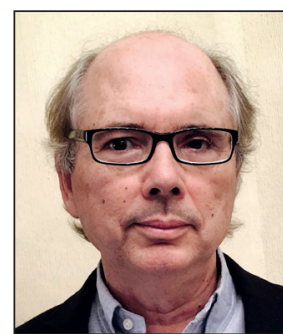

José-Vicente García-Santamaría https://orcid.org/0000-0003-4659-3975

Universidad Carlos III de Madrid

Facultad de Humanidades Comunicación y Documentación

Madrid, 126

28903 Getafe (Madrid), España

jvgsanta@hum.uc3m.es

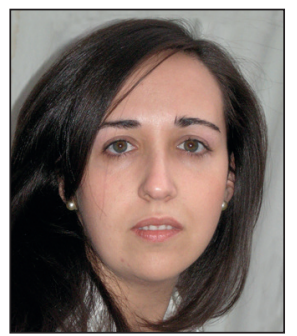

María-José Pérez-Serrano https://orcid.org/0000-0002-2190-7619

Universidad Complutense de Madrid Facultad de Ciencias de la Información Avda. Complutense, 3 28040 Madrid, España mariajoseperezserrano@pdi.ucm.es

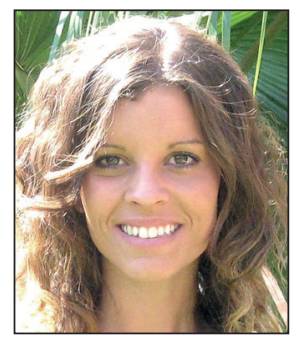

\author{
Miriam Rodríguez-Pallares $\bowtie$ \\ https://orcid.org/0000-0002-5486-0298 \\ Universidad Complutense de Madrid \\ Facultad de Ciencias de la Información \\ Avda. Complutense, 3 \\ 28040 Madrid, España \\ mrpallares@ucm.es
}

\section{Resumen}

La crisis de la Covid-19 ha desestabilizado el sistema comunicativo mundial difuminando algunas de las fronteras de disciplinas como la comunicación política y la comunicación corporativa, o implantando fenómenos nuevos que hasta el momento no se habían conocido, como la competencia del day time televisivo frente al prime time. Este artículo parte del estudio del papel que han tenido los portavoces oficiales en la estrategia de comunicación de crisis del Gobierno de España. Se estudian también los cambios operados en la TV generalista y en abierto, el predominio de la comunicación política sobre la comunicación corporativa, y el papel que han jugado los portavoces gubernamentales como influencers.

\section{Palabras clave}

Portavoces; Comunicación de crisis; Comunicación corporativa; Comunicación política; Sistema de medios; Audiencias televisivas; Influencers; Covid-19; Coronavirus; Pandemias.

\section{Abstract}

The covid-19 crisis has destabilized the world communication system, blurring some of the borders between disciplines such as political communication and corporate communication, and implanting as yet unknown, new phenomena such as the competition between daytime versus primetime television. This article studies the role that official spokespersons

Financiación

Este artículo se encuadra dentro del Proyecto de Investigación CSO2017-88620-P, financiado por la Agencia Española de Investigación dentro del Plan Estatal de Investigación Científica y Técnica y de Innovación 2013-2016. 
have played in the Spanish Government's crisis communication strategy. The changes in free-to-air television, the predominance of political communication over corporate communication, and the role of Government spokespersons as influencers are also studied.

\section{Keywords}

Spokespersons; Spokesmen; Crisis communication; Corporate communication; Media system; Television audiences; Influencers; Covid-19; Coronavirus; Pandemics.

\section{Introducción}

La Covid-19 ha desestabilizado buena parte del entramado comunicativo mundial causando un considerable desajuste. Nunca hasta ahora algunas de sus fronteras habían estado tan poco delimitadas, como es el caso de la comunicación corporativa y la comunicación política, o ese revival de la televisión generalista en abierto, que no solo ha conocido la mayor audiencia de su historia durante el mes de abril de 2020 (Barlovento Comunicación, 2020b), sino que también sus informativos, e, incluso, determinados magazines, han concitado audiencias millonarias. Ha vuelto a confirmarse lo que ya había asegurado en su último informe la Asociación de la Prensa de Madrid (APM): una buena parte de la población española se informa de las noticias a través de la televisión (APM, 2019). Y, en situaciones críticas, este tipo de medios son los que consiguen porcentajes más elevados en el consumo de noticias, obteniendo, además, una valoración positiva de su cobertura informativa (Casero-Ripollés, 2020).

Una crisis es siempre una situación excepcional que puede socavar el prestigio y la reputación de cualquier institución (Fita, 2004). Pero realmente sobreviene cuando los problemas pasan a ser de dominio público y

"provocan fuertes corrientes de opinión, que influyen en los comportamientos de diferentes públicos" (De-laCierva, 2009, p. 162).

De ahí que Rosillo (2018), uno de los mayores expertos en comunicación de crisis en España, subraye que la primera tarea a realizar es identificar y evaluar su importancia y su nivel de gravedad.

Las crisis impactan así en el funcionamiento de una organización, provocando daños de cierta consideración, y con frecuencia, irreparables (Coombs, 2015). En esta situación de enorme estrés (Sartre, 2008) los portavoces mediáticos elegidos son los que llevan un peso muy importante de la comunicación con los media y, en muchos casos, ejercen también como verdaderos influencers ante la opinión pública. Pero, como conocen bien los profesionales de la comunicación que han tenido que gestionar importantes crisis en los más variados sectores, estas situaciones son también como un iceberg: la masa de hielo que emerge fuera del agua constituye la visibilidad y la imagen (Carrascosa, 2003, p. 117), mientras que la parte sumergida es aquella que pocas veces llega a conocerse al no ser visible para el conjunto de la ciudadanía.

Por tanto, la primera tarea a resolver en una situación de crisis es evaluar detenidamente los riesgos reales, tanto actuales como futuros (Berceruelo, 2016), porque los mensajes que se emitan y las actuaciones que se adopten deberán adecuarse a esa información e influirán asimismo sobre la graduación del nivel de alerta que se quiera trasladar a la población.

\section{Contexto científico}

\subsection{Crisis}

El campo de la comunicación de crisis ha desarrollado sus propias teorías, si bien las que se suelen aplicar proceden frecuentemente de la Comunicación, la Sociología y la Psicología, lo que pone de manifiesto que los especialistas se benefician de los avances en otros campos de las Ciencias Sociales. Hay que tener en cuenta igualmente que los principios teóricos tienden a cambiar o a mutar, por lo que es conveniente testarlos regularmente (Fearn-Banks, 2017, p. 17). De ahí que autores como Sellnow y Seeger (2013, p. 2) indiquen que las crisis son, por definición, acontecimientos interdisciplinarios y, a menudo, con un alcance regional en los terrenos político, económico y cultural. No deja de ser relevante, por tanto, que una de las características fundamentales de toda crisis sea su transversalidad, puesto que

“son siempre técnicas, económicas, políticas, corporativas y jurídicas" (Libaert, 2010, p. 25).

Existe así una abundante bibliografía académica que aborda las respuestas que deben ofrecer las organizaciones durante una crisis y cómo deben responder a las diferentes audiencias en una situación de tanta gravedad. Y aunque las reflexiones sobre cuestiones de portavocía no sean muy abundantes, y menos aquellas que estudian el papel de un portavoz en situaciones comprometidas, sí existe -a nivel mundial- un buen número de ensayos sobre las categorías en las que pueden encuadrarse los diferentes tipos de crisis. En este sentido, las crisis sanitarias (Holmes et al., 2009; Lowrey et al., 2006) forman parte de los tipos habituales de categorización de estos fenómenos, al igual que las tecnológicas, industriales o de desastres naturales. Por tanto, la comunicación "emerging infection disease" (EID) se ha unido a ellas, constatándose en estas situaciones de emergencia que las apelaciones al miedo son muy efectivas para condicionar las opiniones y los comportamientos, transformándose así en un importante factor de influencia (Rodríguez-Andrés, 2011).

Puesto que un plan de crisis no es más que un programa normativo que determina las pautas de comportamiento corporativo ante una emergencia (Villafañe, 1993, p. 296) y aunque no existen reglas para garantizar una gestión efectiva, sí conviene seguir ciertos pasos o guías de buenas prácticas basadas en experiencias previas (Seeger, 2007). Las crisis necesitan ser 
previamente protocolizadas y contar con su correspondiente "Manual"; es decir, con un documento operativo en el que se hayan diseñado los posibles escenarios de confrontación que puedan producirse (Capriotti, 2005). Ese Manual dispondrá, también, de su homónimo correspondiente a las funciones, que marque con exactitud los diferentes roles a tener en cuenta; entre ellos, quién o quiénes ejercerán de portavoces y qué labor concreta llevarán a cabo durante las diferentes fases.

Una comunicación profesional huye, por tanto, de la improvisación, y se preocupa por diseñar previamente una "cartografía de riesgos" con todos los escenarios posibles. Así, procura acertar en la gravedad que pueden alcanzar determinados conflictos, sin intentar minimizar sus consecuencias para no difuminar de facto la necesaria sensibilidad y empatía en el abordaje de estos procesos. En consecuencia, una vez que se ha producido la crisis e identificado su importancia, la primera tarea que se debe poner en marcha es una estrategia de comunicación que tenga en cuenta los rasgos morfológicos de una situación que, como la del Coronavirus, podemos encuadrar en la tipología de "catástrofes". Este tipo de desequilibrios suelen tener un gran impacto en la sociedad; con un fuerte golpe inicial que se irá graduando de acuerdo con el desarrollo de la pandemia, el número total de afectados y la transparencia de los emisores. Como subrayan Coombs y Holladay (2012, p. 7), en la gestión de una crisis, el componente crítico es siempre la gestión de la comunicación, y, por supuesto, el papel del comité de crisis y de los portavoces encargados de velar por su buena marcha.

Pero abordar la comunicación en esta tesitura es también gestionar credibilidad, lo que no quiere decir que haya que

"contarlo absolutamente todo, sino saber gestionar verdades" (Túñez, 2012, p. 185).

La transparencia se convierte, así, en la palabra clave de la comunicación de crisis (Westphalen; Libaert, 2008, p. 65). Como norma general, algunos autores (López-Tello, 2006) afirman que no se trata tanto de tener las respuestas adecuadas a todas las preguntas que se formulen, sino de atender y tratar de responder a aquellas cuestiones que permitan a la organización mantener una postura estratégica antes y después de la crisis. La fase de respuesta es el momento más crítico de cómo manejarla, porque los niveles tan altos de confusión, desorientación, incertidumbre, shock y estrés invaden a los líderes de las organizaciones (Seeger; Sellnow; Ulmer, 2003).

Por otra parte, existen tantas respuestas como situaciones de crisis. Cuando un buen número de autores (Barquero; Barquero, 2010; Cervera-Fantoni, 2004; Coombs, 2015; Losada-Díaz, 2018; Paniagua, 2004; Taylor; Kent, 2007; Túñez, 2007) insisten en la necesidad de anticiparse a ellas es porque las primeras 24 horas -las denominadas golden hoursson decisivas, sobre todo si hablamos de accidentes, catástrofes naturales o acontecimientos similares.

Obviamente, para llevar una óptima gestión de cualquiera de estas situaciones de riesgo es preciso ganar la batalla de la opinión pública, y, claro está, sumar a la causa al mayor número de aliados y de medios de comunicación posibles. Como es sabido, las crisis se juegan hoy día en dos frentes fundamentales: las redes sociales -más difíciles de controlar-, y los medios masivos, como la televisión generalista y en abierto (García-Santamaría, 2019).

\subsection{La figura del portavoz}

El portavoz se ha convertido en una figura esencial en la construcción y el mantenimiento de la reputación de la imagen de cualquier institución o compañía. Es la persona autorizada para hablar en nombre de un colectivo, tanto a públicos internos como a externos, y representa la misión, visión y valores de la entidad o de la institución (Camacho-Marquina, 2017, p. 37).

Los atributos de un buen portavoz son muy variados y van desde la empatía y la auctoritas a la credibilidad o la capacidad de síntesis y de divulgación (Arceo, 2012). Y, naturalmente, la construcción del mensaje es la parte esencial de la comparecencia de cualquier portavoz (Ramírez-de-la-Piscina, 2007). Junto a esa parte discursiva, son también factores esenciales -tomando prestadas metodologías de análisis de films (Marzal-Felici; Gómez-Tarín, 2007, pp. 50-51)-:

- la correspondiente puesta en escena;

- los recursos expresivos y narrativos (duración, iluminación, decorado, vestuario, maquillaje y encuadre);

- la interpretación actorial (gestualidad, dicción e interpretación);

es decir, todo aquello que se conoce como lenguaje no verbal, así como los recursos narrativos: guion, relato, narración y diégesis.

El setting es la parte fundamental de la puesta en escena y puede asumir papeles narrativos, si bien existen elementos dentro de estos escenarios que pueden por sí solos ser portadores de una específica función semántica. Los portavoces, por consiguiente, se construyen a partir de su actuación ante las cámaras de televisión, y en esta interpretación actorial son elementos importantes el vestuario, el maquillaje y el uso de la iluminación. El vestuario en los hombres tiende a ser más neutro (vestimenta canónica con el uso de traje de color gris o azul), y de no ser así puede contribuir a crear o reforzar un determinado tipo de personaje que llegue a cumplir una función específica como elemento articulador del significado (Carmona, 2002, pp. 130-131). En este contexto, la actuación del coordinador de emergencias en la crisis de la Covid-19 en España, Fernando Simón, fue muy significativa.

Otro tema, objeto siempre de controversia, es la elección del perfil idóneo para la designación de esa figura, puesto que rara vez van unidas las competencias correspondientes a ambos perfiles: ¿técnico o comunicador? Del mismo modo, el debate suele centrarse habitualmente -sobre todo en crisis de grandes dimensiones o que ocurran en sectores muy especializados- en el número de portavoces que podremos utilizar, y, lógicamente, en el rol que deberá desempeñar cada uno para que no se contradigan y exista así un único planteamiento discursivo. 
La formación regular de estos portavoces es una tarea esencial que muchos departamentos de comunicación de aquellas compañías que corren un mayor riesgo de enfrentarse a situaciones críticas (empresas de transporte, químicas, petroleras, sanidad) tratan de forma habitual varias veces al año. El training clásico de un buen portavoz en tiempos de coronavirus debería apelar en el comienzo de su intervención a conocer cuánto dura o debería durar su comparecencia, porque no es lo mismo preparar un discurso de una hora que uno de diez minutos. Una vez que la intervención haya dado comienzo convendría esbozar una síntesis de su contenido, así como las pautas a seguir para que la audiencia pueda prever qué asuntos se van a tratar. A continuación, es conveniente ir directamente a los asuntos importantes, sin circunloquios, utilizando frases cortas, huyendo de los tonos monocordes y enfatizar al menos las partes más importantes de la disertación. Obviamente, el recurso de citar autoridades en la materia -al margen de los expertos oficiales- puede y debe respaldar muchos argumentos. Conviene recordar también que es necesario primar, en muchos casos, la "información de servicio" sobre las alocuciones grandilocuentes y de carácter ideológico-político. Y, finalmente, no olvidar nunca -al ser la televisión el medio más seguido- que se debe utilizar un lenguaje comprensible para la mayoría de la ciudadanía. La jerga administrativa es siempre lo opuesto a una buena comunicación.

Otras recomendaciones utilizadas en la formación de portavoces hacen referencia a la necesidad de conocer a fondo lo que se desea comunicar, ya que las audiencias recuerdan sobre todo dos cosas: los conceptos y la idea global; y después, la comunicación emocional (Álvarez; Caballero, 1997, p. 94). A este planteamiento suele ayudar el consabido "argumentario". Gracias a su elaboración, una organización pone en común sus conocimientos, unifica sus respuestas y facilita el trabajo de comunicación de sus portavoces (Arroyo; Yus, 2011, p. 55). Naturalmente, existen variadas formas de argumentarios, pero los más subliminales, es decir, aquellos que no tienen necesidad de recurrir a estrategias macrodiscursivas suelen ser los más eficaces.

Por lo que respecta a las comparecencias públicas, los portavoces más expertos tienen a gala presentarse solos y de pie ante los periodistas. Es el método preferido por la cúpula de muchas organizaciones y una técnica muy presidencial, porque suele transmitir una imagen de soledad que, probablemente, ayude a dotar de un mayor poder simbólico el liderato de quien se presenta ante los medios. Y, en el caso contrario, la comparecencia simultánea de varios portavoces, agrupando así efectivos -como se ha producido en muchas fases de la pandemia del coronavirus-, responde a una idea muy concreta: vehicular la imagen del trabajo en equipo y de coordinación entre diferentes departamentos.

\section{Fundamentos metodológicos}

El planteamiento gnoseológico de este trabajo se establece en varios planos que se desglosan a continuación y que se plantean imprescindibles dada la dificultad de aprehensión de la realidad analizada por la contemporaneidad de los hechos, que no permite la distancia objetiva entre lo estudiado y el sujeto investigador.

En primer lugar, la escalera disectiva, es decir, las research questions (RQ's), los objetivos y la hipótesis. Las primeras son las siguientes:

RQ1: ¿Cuáles son los rasgos distintivos de los portavoces en el contexto de crisis de la Covid-19?

RQ2: ¿La comunicación política ha sustituido a la comunicación de crisis en la gestión de la Covid-19?

RQ3: ¿Cómo ha cambiado el consumo y la parrilla de televisión en base a una traslación temporal del prime time al concepto day time?

El objetivo es analizar el papel de los portavoces protagonistas de la gestión de la crisis de la Covid-19 en España, a partir de la teoría de comunicación de crisis y teniendo en cuenta la impronta de sus acciones en el funcionamiento de la TV generalista y en abierto en los ritmos y estrategias internas de la televisión generalista (OG). Y la hipótesis de partida o, en palabras de Kerlinger y Lee (2002), la preposición conjetural es la siguiente:

"la gestión de la imagen pública de los portavoces, la estructura de la parrilla de televisión y la articulación de la comunicación de crisis han llegado a ser tres de las variables más importantes en el cambio del sistema comunicativo derivado de la crisis de la Covid-19 en España".

En segundo lugar, la metodología, que se vertebra a partir de métodos heurísticos como son:

- Para los portavoces: el análisis de contenido, aplicado bajo la perspectiva de la Teoría dramatística de Burke desde el paradigma de Zurutuza-Muñoz (2014).

- Para la comunicación de crisis y la parrilla audiovisual:a partir de la premisa anterior, se fundamenta en herramientas reflexivo-discursivas, consecuencia de la disección de datos aportados por la consultora audiovisual y digital Barlovento Comunicación, principalmente, sobre la audiencia de los canales que cuentan con informativos protagonistas del sistema audiovisual en abierto en España y en los que confluyen, además, el porcentaje más importante de audiencia global y un perfil de espectador heterogéneo, es decir, La 1 de TVE, de la CRTVE; Antena 3 y La sexta, de Atresmedia Corporación de Medios de Comunicación S.A., y Telecinco, de Mediaset España Comunicación, S.A.

Y métodos didácticos (orientados a la exposición y transmisión de conocimiento) como la correlación, que sirve para hacer el paralelismo entre los tres elementos del análisis (portavoces, comunicación de crisis y estructura de la comunicación) y la deducción. 
Tabla 1. Ficha técnica de la investigación

\begin{tabular}{|l|l|}
\hline Ámbito geográfico & España \\
\hline Método & Análisis de contenido \\
\hline Método de recogida de información & Muestra no probabilística \\
\hline Universo & $\begin{array}{l}150 \text { vídeos de las comparecencias asociadas a la crisis de la Covid-19 alojadas en el portal } \\
\text { https://www.lamoncloa.gob.es/multimedia/videos/Paginas/index.aspx }\end{array}$ \\
\hline Muestra & $\begin{array}{l}20 \%->30 \text { vídeos (11 h. } 56 \text { min. } 5 \text { seg.) }->52 \text { comparecencias } \\
\text { Elección realizada en función de tres criterios: } \\
\text { 1) Tiene que haber una comparecencia pública, conferencia o rueda de prensa. } \\
\text { 2) Se excluyen las reuniones o el material técnico que no cumplan la premisa anterior. } \\
\text { 3) Debe identificarse una interacción entre el portavoz y la sociedad en su conjunto desde la sede del } \\
\text { Gobierno (no en sede parlamentaria). }\end{array}$ \\
\hline Fechas del trabajo de campo & \begin{tabular}{l}
$30 / 04 / 2020$ - $16 / 05 / 2020$ \\
\hline
\end{tabular} \\
\hline
\end{tabular}

Nota: Según fuentes oficiales de La Moncloa, desde el 12 de marzo hasta el 26 de abril, el presidente del Gobierno, los miembros del Ejecutivo y los portavoces del Comité de Gestión Técnica han comparecido en un total de 110 ocasiones, y respondido a 1.020 preguntas, desglosadas en 11 comparecencias telemáticas del presidente del Gobierno; 43 ruedas de prensa telemáticas del Comité Técnico de Gestión del Coronavirus; 53 ruedas de prensa telemáticas de ministros, y otras tres ruedas de prensa telemáticas.

De todo ello se desprende que este estudio se aleja de un análisis de contenido al uso y se acerca a un análisis multidimensional que abarca tanto cuestiones objetivables -como pueden ser la duración del discurso o el manejo de datos cuantitativos-como otras que están asociadas a actitudes, aptitudes, comportamientos y competencias. De ahí también que el estudio sincrónico de cada una de las unidades de análisis arroje resultados parciales que, visto el período analizado de manera diacrónica (como sucede con la comunicación de crisis y la estructura televisual), podría tener igualmente otros correlatos que las complementasen.

En tercer, y último lugar, los límites de la investigación, que vienen marcados por las fechas-clave de la pandemia del coronavirus en España, y sus márgenes se circunscriben a los que se pueden considerar los tres planos del discurso en la crisis de la Covid-19:

1) Antes del confinamiento (4 al 12 de marzo de 2020).

2) Momento clave de la pandemia: máximo confinamiento (12 de marzo de 2020 a 31 de marzo de 2020) y prolongación del estado de alarma ( 1 al 13 de abril de 2020).

3) Progresiva apertura y desescalada (13 de abril al 30 de abril de 2020).

\section{Análisis}

A continuación, se aborda de manera diferenciada el análisis de las tres esferas anunciadas: portavoces, comunicación de crisis y claves televisivas en tiempos de la Covid-19 en nuestro país.

\subsection{Cartografía analítica de los portavoces}

Con el fin de entender qué y cómo se ha estudiado la figura del portavoz y, por tanto, de dónde se extraen las conclusiones, es imprescindible explicitar cuáles son las herramientas empleadas y sobre quién o quiénes se han utilizado. En este sentido, lo primero que se debía seleccionar eran los vídeos que iban a servir de muestra y, por tanto, debíamos fijar los siguientes criterios:

- El universo del estudio no atiende a la clasificación de vídeos Covid-19 planteada por La Moncloa; es decir, la revisión de vídeos se hace de forma manual.

- El vídeo tiene que contener una comparecencia pública: conferencia o rueda de prensa.

- Se excluyen las reuniones o el material técnico que no cumplan la premisa anterior. Debe identificarse una interacción entre el portavoz y la sociedad en su conjunto.

- No se analiza el turno de respuestas, con lo cual se focaliza el estudio en el discurso elaborado previamente; esto es, en la planificación estratégica.

- Únicamente se tienen en cuenta las comparecencias y ruedas de prensa llevadas a cabo en el Palacio de la Moncloa, no en sede parlamentaria.

- La selección da comienzo cuando aparece el término "coronavirus" (9 de marzo de 2020) en los descriptores de las comparecencias públicas recogidas en https://www.lamoncloa.gob.es

De un universo de 150 vídeos, la muestra seleccionada para el estudio se acota a 30, que suman casi 12 horas de visionado. Ver tabla 2:

https://figshare.com/s/e39eaedbfac878cd93ff 
Tabla 2. Portavoces objeto de estudio y tiempos de aparición en la muestra

\begin{tabular}{|c|c|c|c|c|c|c|c|}
\hline Núm. & & Nombre & Cargo & Total & $\begin{array}{l}\text { Porcentaje } \\
\text { de } \\
\text { aparición } \\
\text { (sobre el } \\
\text { total) }\end{array}$ & $\begin{array}{l}\text { Porcentaje } \\
\text { de } \\
\text { aparición } \\
\text { solo }\end{array}$ & $\begin{array}{l}\text { Porcen- } \\
\text { taje de } \\
\text { aparición } \\
\text { acompa- } \\
\text { ñado }\end{array}$ \\
\hline 1 & \multicolumn{2}{|c|}{$\begin{array}{l}\text { Pedro Sánchez } \\
\text { Pérez-Castejón }\end{array}$} & $\begin{array}{l}\text { Presidente del Gobierno de } \\
\text { España }\end{array}$ & 11,00 & 36,67 & 100,00 & 0,00 \\
\hline \multirow{2}{*}{2} & \multirow{2}{*}{\multicolumn{2}{|c|}{ Fernando Simón Soria }} & $\begin{array}{l}\text { Director del Centro de Coordi- } \\
\text { nación de Alertas y Emergencias } \\
\text { Sanitarias (CCAES) del Ministerio } \\
\text { de Sanidad }\end{array}$ & \multirow{2}{*}{5,5} & \multirow{2}{*}{18,33} & \multirow{2}{*}{36,36} & \multirow{2}{*}{63,64} \\
\hline & & & $\begin{array}{l}\text { Portavoz del Ministerio de Sani- } \\
\text { dad para la pandemia del SARS- } \\
\text { CoV-2 de } 2020 \text { / Comité Técnico de } \\
\text { Gestión del coronavirus Covid-19 }\end{array}$ & & & & \\
\hline \multirow{4}{*}{$\begin{array}{l}\text { Ministros que } \\
\text { forman parte del } \\
\text { Comité Técnico de } \\
\text { Gestión del coro- } \\
\text { navirus Covid-19 a } \\
\text { fecha } 13 \text { de abril } \\
\text { de } 2020\end{array}$} & 3 & Salvador Illa Roca & Ministro de Sanidad & 3,75 & 12,50 & 26,67 & 73,33 \\
\hline & 4 & $\begin{array}{l}\text { Margarita Robles } \\
\text { Fernández }\end{array}$ & Ministra de Defensa & 1,25 & 4,17 & 0,00 & 100,00 \\
\hline & 5 & $\begin{array}{l}\text { Fernando Grande- } \\
\text { Marlaska Gómez }\end{array}$ & Ministro de Interior & 2,75 & 9,17 & 0,00 & 100,00 \\
\hline & 6 & José Luis Ábalos Meco & $\begin{array}{l}\text { Ministro de Transportes, Movili- } \\
\text { dad y Agenda Urbana }\end{array}$ & 1,75 & 5,83 & 0,00 & 100,00 \\
\hline 7 & \multicolumn{2}{|c|}{ Pablo Iglesias Turrión } & $\begin{array}{l}\text { Vicepresidente segundo del } \\
\text { Gobierno de España y Ministro } \\
\text { de Derechos Sociales y Agenda } \\
2030 \text { de España }\end{array}$ & 0,50 & 1,67 & 0,00 & 100,00 \\
\hline \multirow{6}{*}{$\begin{array}{l}\text { Técnicos y } \\
\text { uniformados } \\
\text { (que aparecen } \\
\text { en los vídeos de } \\
\text { muestra) }\end{array}$} & \multirow{6}{*}{8} & María José Rallo & Secretaria General de Transportes & \multirow{6}{*}{3,50} & \multirow{6}{*}{11,67} & \multirow{6}{*}{0,00} & \multirow{6}{*}{100,00} \\
\hline & & Miguel A. Villarroya & Jefe Estado Mayor de la Defensa & & & & \\
\hline & & José Ángel González & $\begin{array}{l}\text { Comisario y Director Operativo } \\
\text { de la Policía Nacional }\end{array}$ & & & & \\
\hline & & Laurentino Ceña & $\begin{array}{l}\text { Director Operativo de la Guardia } \\
\text { Civil }\end{array}$ & & & & \\
\hline & & José M. Santiago & Jefe Estado Mayor Guardia Civil & & & & \\
\hline & & Carlos Pérez & $\begin{array}{l}\text { Director Gabinete Estado Mayor } \\
\text { de la Defensa }\end{array}$ & & & & \\
\hline \multicolumn{4}{|c|}{ Total de vídeos analizados } & 30 & 100,00 & & \\
\hline
\end{tabular}

Nota sobre la codificación: Puede parecer singular la cuantificación con decimales en la columna "total". Estos derivan de que se ha puntuado con un número entero (1) cuando el protagonista aparece solo y se contabiliza como fracción, dividiendo el 1 entre el número de personas que están presentes en la comparecencia.

A partir de su análisis se ha podido identificar la incidencia mediática de los portavoces en relación a su porcentaje de presencia en comunicaciones públicas. Ver figuras 18 y 19:

https://figshare.com/s/e39eaedbfac878cd93ff

El análisis de los portavoces se ha trabajado con la Teoría Dramatística de Burke bajo el paradigma de Zurutuza Muñoz (2014), pero adaptado a la naturaleza y especificidad del objeto de estudio. Para cada uno de los indicadores estudiados se ha fijado un "argumentario" o tesauro, que objetiva y da fiabilidad, y se ha aplicado una escala Likert con el fin de gradar en cuatro niveles cada uno de ellos.

El "argumentario" o tesauro es el siguiente:

1. Auctoritas: capacidad moral para emitir opiniones cualificadas, y que solo puede emanar del dominio de los temas de los que se está hablando. Depende, en este análisis, del cargo de la persona que habla y de su vinculación con la crisis Covid-19.

2. Empatía: destreza para ponerse en el lugar del otro o de la audiencia. Los expertos en comunicación recomiendan comenzar siempre una alocución en situaciones de crisis recordando a los muertos o damnificados y al dolor que sienten sus familias. Se puntúa de forma más elevada cuando se hace alusión directa a las víctimas.

3. Capacidad de divulgación: habilidad para traducir elevados o alambicados conceptos en explicaciones sencillas y comprensibles para grandes audiencias. En este análisis, se obtiene mayor puntuación cuando el portavoz hace un discurso asequible y fácil de entender. 
Tabla 3. Matriz de análisis del rol del portavoz y de la comunicación de crisis

\begin{tabular}{|c|c|c|c|c|c|c|c|c|}
\hline Analista & & & \multicolumn{2}{|c|}{ Fecha de análisis } & & & & \\
\hline \multicolumn{9}{|c|}{ Video núm. .... } \\
\hline \multicolumn{2}{|l|}{ Fecha } & Título & \multicolumn{2}{|c|}{ Identificador / Observaciones } & \multicolumn{4}{|c|}{ Protagonista / s } \\
\hline \multirow[b]{2}{*}{ Núm. } & \multirow[b]{2}{*}{ Denominación } & \multirow[b]{2}{*}{ Concepto } & \multirow{2}{*}{\multicolumn{2}{|c|}{ Indicadores / Tesauro }} & \multicolumn{4}{|c|}{ Escala Likert } \\
\hline & & & & & $\begin{array}{l}0=> \\
\text { nada }\end{array}$ & $\begin{array}{l}1=> \\
\text { poco }\end{array}$ & $\begin{array}{l}2=> \\
\text { bastante }\end{array}$ & $\begin{array}{l}3=> \\
\text { mucho }\end{array}$ \\
\hline 1 & $\begin{array}{l}\text { La escena de la } \\
\text { comunicación } \\
\text { (macro-análisis) }\end{array}$ & $\begin{array}{l}\text { La péntada dramatística de Burke (19 } \\
\text { cribir la escena en la que tiene lugar } \\
\text { En este caso se entiende por macro- } \\
\text { política seguida por las televisiones } \\
\text { mente, La 1, Antena 3, La sexta y Tele }\end{array}$ & $\begin{array}{l}\text { 69) e } \\
\text { a cor } \\
\text { nális } \\
\text { ener } \\
\text { inco) }\end{array}$ & $\begin{array}{l}\text { "la herramienta para des- } \\
\text { unicación del Gobierno". } \\
\text { el que concierne a la } \\
\text { listas en abierto (principal- }\end{array}$ & No apl & & & \\
\hline \multirow{7}{*}{2} & \multirow{7}{*}{$\begin{array}{l}\text { La comunicación } \\
\text { en la escena (mi- } \\
\text { cro-análisis) }\end{array}$} & \multirow{7}{*}{$\begin{array}{l}\text { Incluye las categorías que estudian } \\
\text { los elementos comunicativos ver- } \\
\text { bales y no verbales. Incorpora así } \\
\text { las categorías que estudian el rol y } \\
\text { el trabajo de los portavoces }\end{array}$} & 1 & Auctoritas & & & & \\
\hline & & & 2 & Empatía & & & & \\
\hline & & & 3 & $\begin{array}{l}\text { Capacidad de divulga- } \\
\text { ción }\end{array}$ & & & & \\
\hline & & & 4 & $\begin{array}{l}\text { Capacidad de síntesis y } \\
\text { de exposición }\end{array}$ & & & & \\
\hline & & & 5 & Uso de datos & & & & \\
\hline & & & 6 & Autocontrol y discreción & & & & \\
\hline & & & 7 & Ritual escénico & & & & \\
\hline \multirow{5}{*}{3} & \multirow{5}{*}{ Categoría narrativa } & \multirow{5}{*}{$\begin{array}{l}\text { Aplica la aportación de Heath } \\
\text { (2004) a los aspectos más discursi- } \\
\text { vos. Se analizan las declaraciones } \\
\text { del Gobierno midiendo su respues- } \\
\text { ta a esa exigencia retórica a través } \\
\text { de su narración de la crisis (rol del } \\
\text { portavoz, ritmo de comunicación } \\
\text { y relaciones con los medios)". In- } \\
\text { cluyen las categorías que estudian } \\
\text { propiamente la comunicación de } \\
\text { crisis }\end{array}$} & 8 & Confusión y opacidad & & & & \\
\hline & & & 9 & Transparencia & & & & \\
\hline & & & 10 & Duración del discurso & & & & \\
\hline & & & 11 & Narración & & & & \\
\hline & & & 12 & Información de servicio & & & & \\
\hline 4 & $\begin{array}{l}\text { Categoría de reso- } \\
\text { nancia cultural }\end{array}$ & \multicolumn{3}{|c|}{$\begin{array}{l}\text { No aplica en este análisis por encontrase fuera de la cobertura analíti- } \\
\text { ca de este trabajo }\end{array}$} & \multicolumn{4}{|c|}{ No aplica } \\
\hline 5 & $\begin{array}{l}\text { Categoría de autori- } \\
\text { dad democrática }\end{array}$ & \multicolumn{3}{|c|}{$\begin{array}{l}\text { No aplica en este análisis por encontrase fuera de la cobertura analíti- } \\
\text { ca de este trabajo }\end{array}$} & \multicolumn{4}{|c|}{ No aplica } \\
\hline
\end{tabular}

Fuente: Zurutuza-Muñoz (2014)

4. Capacidad de síntesis y exposición: capacidad de sintetizar ideas clave en breves segundos y explicar, en no más de uno o dos minutos, cualquier argumentación, por compleja que sea. Se rehúsan las construcciones muy complejas, salvo que el objetivo sea solamente ocupar espacio en los telediarios -una estrategia habitual en muchas empresas cuando buscan que presentar resultados empresariales poco sólidos o cuando no quieren dar ningún titular-. En este análisis, se valora positivamente el hecho de que en los dos minutos iniciales se puedan contar cosas muy relevantes.

5. Uso de datos: los datos casi siempre suenan veraces, son más complicados de desmentir y pueden resultar comprensibles para grandes audiencias. Además, suelen cargar de razones a los portavoces.

6. Autocontrol y discreción: soltura para no perder la compostura ni olvidar que, como portavoz, es un servidor público.

7. Ritual escénico: muestra de cierto dominio teatral en los gestos y en las pausas programadas.

8. Confusión y opacidad: tendencia a ofrecer datos poco claros; contradicciones y cambios de criterio.

9. Transparencia: se entiende, en este análisis, como un atributo esencial en situaciones de paroxismo. La puntuación en esta categoría responde a cuestiones como: ¿son públicas las estadísticas; las composiciones de los diferentes comités; el dinero empleado en el pago a proveedores o la forma de efectuar contrataciones millonarias con terceros?

10. Duración del discurso: tendencia a la dilatación innecesaria de un mensaje. 
11. Narración: capacidad de contar historias. El storytelling siempre ha primado las "historias de superación", o, dicho de otra manera, "sin superación es muy difícil construir storytelling". Hay que responder, por consiguiente, a la pregunta: ¿se han narrado historias en las intervenciones de portavoces que sean realmente una herramienta de generación de empatía?

12. Información de servicio: oferta de información práctica y útil que la población de un Estado debe conocer para sobrellevar situaciones de pandemia y confinamiento.

\subsubsection{Resultados}

Después del visionado, la batería de datos ha arrojado resultados que pivotan, en primer lugar, sobre lo cuantitativo. Y, más tarde, permiten hacer inferencias más genéricas, gracias a una elevación analítica.

Tabla 4. Presidente del Gobierno, Pedro Sánchez (datos en \%)

\begin{tabular}{|c|c|c|c|c|c|c|c|}
\hline \multicolumn{3}{|c|}{ Total comparecencias analizadas $=11$} & $0=$ nada & $1=$ poco & 2 = bastante & $3=$ mucho & Resultados \\
\hline \multirow{7}{*}{$\begin{array}{l}\text { La comunicación } \\
\text { en la escena } \\
\text { (micro-análisis) }\end{array}$} & 1 & Auctoritas & 0,00 & 0,00 & 36,36 & 63,64 & 87,88 \\
\hline & 2 & Empatía & 0,00 & 0,00 & 27,27 & 72,73 & 90,91 \\
\hline & 3 & Capacidad de divulgación & 0,00 & 27,27 & 36,36 & 36,36 & 69,70 \\
\hline & 4 & Capacidad de síntesis y de exposición & 9,09 & 54,55 & 18,18 & 18,18 & 48,48 \\
\hline & 5 & Uso de datos & 9,09 & 54,55 & 27,27 & 9,09 & 45,45 \\
\hline & 6 & Autocontrol y discreción & 0,00 & 0,00 & 9,09 & 90,91 & 96,97 \\
\hline & 7 & Ritual escénico & 0,00 & 0,00 & 18,18 & 81,82 & 93,94 \\
\hline \multirow{5}{*}{$\begin{array}{l}\text { Categoría narra- } \\
\text { tiva }\end{array}$} & 8 & Confusión y opacidad & 36,36 & 63,64 & 0,00 & 0,00 & 21,21 \\
\hline & 9 & Transparencia & 0,00 & 63,64 & 18,18 & 18,18 & 51,52 \\
\hline & 10 & Duración del discurso & 9,09 & 63,64 & 18,18 & 9,09 & 42,42 \\
\hline & 11 & Narración & 0,00 & 9,09 & 27,27 & 63,64 & 84,85 \\
\hline & 12 & Información de servicio & 0,00 & 18,18 & 45,45 & 36,36 & 72,73 \\
\hline & & & & & & Media & 67,17 \\
\hline
\end{tabular}

El presidente del Gobierno tuvo a lo largo de los meses de marzo y abril un total de 60 apariciones (recogidas por el Pool Moncloa en la sección de vídeos: 20,76\%), de las que 16 fueron comparecencias y ruedas de prensa. Todas ellas profusamente recogidas por los medios de comunicación, y, especialmente, por la televisión generalista.

El análisis sincrónico de los vídeos seleccionados de Pedro Sánchez (tabla 4) reporta una valoración media para el presidente de 67,2/100. Dado que el análisis no se ha aplicado a los turnos de preguntas, se puede evidenciar un discurso estudiado, lo que complica identificar cambios notorios en su exposición. El análisis kinésico y paralingüístico (autocontrol y discreción y ritual escénico) se valora positivamente. El tono, el ritmo o el énfasis en determinados momentos del discurso demuestran planificación y destreza en la oratoria -a excepción del día 4 de abril, cuando Sánchez muestra evidentes signos de agotamiento perceptibles en su imagen y su discurso-. Esto es positivo desde el punto de vista de la estrategia comunicativa, pero la repetición de claves paralingüísticas en una misma intervención le hace perder cierto grado de empatía. Por otra parte, el rol de Sánchez como presidente del Gobierno mantiene casi inalterable su auctoritas; sin embargo, la tendencia a la reiteración de contenidos o la extensión innecesaria de sus intervenciones en solitario hacen que esta variable oscile entre las puntuaciones de 2 y 3.

Queda, sin embargo, fuera de cualquier duda que su impacto mediático (medido en términos cuantitativos de audiencia) ha sido considerable, porque dispuso de una intervención propia cada 1,02 días. Las televisiones dedicaron a estos espacios alrededor de una hora o más de programa, coincidiendo con sus telediarios del day time o prime time. En el periodo de tiempo estudiado, y tras las ocho intervenciones, con amplia cobertura de las televisiones generalistas, el presidente del Gobierno contó con un acumulado de audiencia de más de 85 millones, sumando los datos aportados por Barlovento Comunicación. Y a este número tendrían que unirse el resto de sus intervenciones en el Congreso o en diferentes Comités, más difíciles de evaluar con precisión, pero que probablemente superarían de largo los 30-40 millones. Es decir, solamente el presidente concitó ante las pantallas a una audiencia de unos 130 millones de personas durante los meses de marzo y abril. Probablemente, y desde la noche del 23F, ningún gobernante en España, ha gozado de tanta atención en televisión como Pedro Sánchez, quien ha tenido la oportunidad de empatizar, explicar, justificarse y de usar una gran variedad de recursos retóricos destinados a tan amplios públicos.

Mientras tanto, sus ministros ejercieron puntualmente de portavoces contribuyendo a incrementar estas ratios. La mayor parte de ellos -aquellos que no pertenecían al casting diseñado inicialmente o aquellos que no respondieron adecuadamente en sus pruebas mediáticas-, limitaron mucho sus apariciones. Desde el punto de vista cuantitativo, de los 22 ministros de este gabinete, 11 de ellos no tuvieron tanta relevancia en estos temas, aunque -caso de Pablo Iglesias- 
pudieran contar con intervenciones significativas en otros terrenos. Claro está, crear 22 storytellings ministeriales, una hoja de ruta para cada ministerio, y un argumentario claro y preciso para cada uno de ellos suponía una gran labor de construcción y coordinación.

De los 30 vídeos analizados (tabla 2), el ministro que más veces compareció fue Salvador Illa (Sanidad), que aparece en un 12,50\% del tiempo estudiado. La ministra de Defensa, Margarita Robles; el ministro del Interior, Fernando Grande-Marlaska; el ministro de Transportes, José Luis Ábalos, y el vicepresidente segundo del Gobierno, ejercieron de una forma mucho más puntual como altavoces cualificados del Gobierno a lo largo de los dos meses estudiados.

Tabla 5. Mapa de valoraciones de los diferentes "portavoces" en la crisis Covid-19 (\%) en la muestra analizada

\begin{tabular}{|c|c|c|c|c|c|c|c|c|c|c|}
\hline \multicolumn{3}{|c|}{ Total comparecencias analizadas $=\mathbf{5 2}$} & 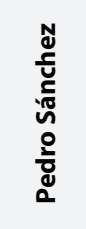 & 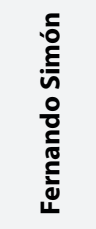 & 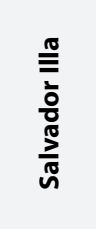 & 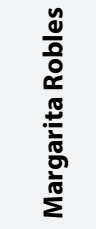 & 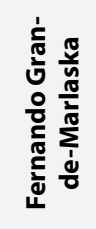 & 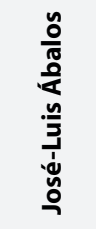 & $\begin{array}{l}\frac{n}{y} \\
\frac{0}{0} \\
\frac{0}{0} \\
\frac{0}{0} \\
0\end{array}$ & 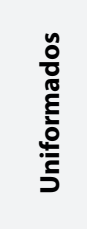 \\
\hline \multicolumn{3}{|l|}{ Comparencias } & 11 & 9 & 8 & 4 & 7 & 5 & 1 & 7 \\
\hline \multicolumn{3}{|l|}{$\%$ del total } & 21,15 & 17,31 & 15,38 & 7,69 & 13,46 & 9,62 & 1,92 & 13,46 \\
\hline \multirow{8}{*}{$\begin{array}{l}\text { La comunicación } \\
\text { en la escena } \\
\text { (micro-análisis) }\end{array}$} & 1 & Auctoritas & 87,88 & 100,00 & 70,83 & 100,00 & 100,00 & 93,33 & 66,67 & 100,00 \\
\hline & 2 & Empatía & 90,91 & 7,41 & 8,33 & 83,33 & 57,14 & 46,67 & 100,00 & 0,00 \\
\hline & 3 & Capacidad de divulgación & 69,70 & 40,74 & 37,50 & 75,00 & 57,14 & 33,33 & 100,00 & 66,67 \\
\hline & 4 & $\begin{array}{l}\text { Capacidad de síntesis y de } \\
\text { exposición }\end{array}$ & 48,48 & 66,67 & 100,00 & 100,00 & 95,24 & 100,00 & 33,33 & 100,00 \\
\hline & 5 & Uso de datos & 45,45 & 100,00 & 62,50 & 50,00 & 52,38 & 53,33 & 33,33 & 66,67 \\
\hline & 6 & Autocontrol y discreción & 96,97 & 100,00 & 95,83 & 100,00 & 100,00 & 100,00 & 66,67 & 100,00 \\
\hline & 7 & Ritual escénico & 93,94 & 7,41 & 91,67 & 100,00 & 100,00 & 93,33 & 66,67 & 100,00 \\
\hline & \multicolumn{2}{|c|}{ Media en el micro-análisis } & 76,19 & 60,32 & 66,67 & 86,90 & 80,27 & 74,29 & 66,67 & 76,19 \\
\hline \multirow{6}{*}{$\begin{array}{l}\text { Categoría } \\
\text { narrativa }\end{array}$} & 8 & Confusión y opacidad & 21,21 & 0,00 & 37,50 & 0,00 & 28,57 & 6,67 & 0,00 & 0,00 \\
\hline & 9 & Transparencia & 51,52 & 66,67 & 37,50 & 41,67 & 38,10 & 60,00 & 33,33 & 33,33 \\
\hline & 10 & Duración del discurso & 42,42 & 100,00 & 100,00 & 66,67 & 95,24 & 80,00 & 100,00 & 76,19 \\
\hline & 11 & Narración & 84,85 & 40,74 & 33,33 & 83,33 & 42,86 & 33,33 & 100,00 & 33,33 \\
\hline & 12 & Información de servicio & 72,73 & 70,37 & 50,00 & 75,00 & 61,90 & 73,33 & 33,33 & 66,67 \\
\hline & \multicolumn{2}{|c|}{ Media en la categoría narrativa } & 54,55 & 55,56 & 51,67 & 53,33 & 53,33 & 50,67 & 53,33 & 41,90 \\
\hline \multirow{2}{*}{ Sobre 100} & \multicolumn{2}{|c|}{ Media por portavoz } & 67,17 & 58,33 & 60,42 & 72,92 & 69,05 & 64,44 & 61,11 & 61,90 \\
\hline & \multicolumn{2}{|c|}{ Media de los portavoces } & \multicolumn{8}{|c|}{64,42} \\
\hline \multirow{2}{*}{ Sobre 10} & \multicolumn{2}{|c|}{ Media por portavoz } & 6,72 & 5,83 & 6,04 & 7,29 & 6,90 & 6,44 & 6,11 & 6,19 \\
\hline & \multicolumn{2}{|c|}{ Media de los portavoces } & \multicolumn{8}{|c|}{6,44} \\
\hline
\end{tabular}

La evaluación media obtenida por el ministro de Sanidad fue un 60,42/100 (tabla 5). La capacidad de síntesis y la no extensión innecesaria de los discursos son los items que mayor valor reportan en el análisis de la muestra analizada. En un rango de sobresaliente se reconoce su ritual escénico o su capacidad de autocontrol y discreción. Sus principales errores a nivel comunicativo se vinculan con la empatía o la capacidad de divulgación, fruto de un tono monocorde, sin énfasis y con una retórica burocrática.

El análisis de las intervenciones de Margarita Robles reporta una media de un 72,92/100. Como en el caso del presidente del Gobierno, obtiene notas máximas en variables relativas al paralingüismo, no merma en ninguna intervención su auctoritas, ni muestra signos de confusión u opacidad evidentes en un análisis individual y sincrónico de sus intervenciones. La transparencia en sus discursos es la variable calificada con menor puntuación (41,67/100).

El ministro de Interior roza el notable como valoración media (69,05/100). Como en el caso de Robles, su auctoritas y sus habilidades paralingüísticas obtienen una valoración máxima. Los signos de confusión y opacidad y la falta de transparencia son sus principales errores comunicativos. Como en el caso del ministro Illa, su habilidad para concretar ideas y evitar dilataciones discursivas innecesarias también se valoran con un rango de sobresaliente.

El ministro de Transportes, Movilidad y Agenda Urbana reporta una media de 64,44/100 en el análisis sincrónico de las intervenciones analizadas. Se valora con la máxima puntuación su capacidad de síntesis y exposición y su autocontrol y discreción. Se puntúan negativamente su capacidad de divulgación y su estructura narrativa, así como la identificación de muestras de confusión y opacidad. 
La calificación obtenida del análisis de Pablo Iglesias es de un 61,11/100. Si bien el vicepresidente segundo y ministro de Derechos Sociales y Agenda 2030 no era uno de los portavoces oficiales elegidos por el Gobierno para la gestión de la Covid-19, compartió protagonismo con otros ministros que sí ostentaban este cargo, con lo que su presencia tiene reflejo en este estudio. En este caso, la empatía, la capacidad de divulgación, la duración del discurso, la ausencia de confusión y opacidad y la buena estructura narrativa obtienen valoraciones máximas; lo que coincide con las habilidades de oratoria demostradas en otras ocasiones; mientras que la capacidad de síntesis, el uso de datos y la transparencia o la oferta de información de servicio como protagonista en sus intervenciones son las variables que menos puntuación reciben.

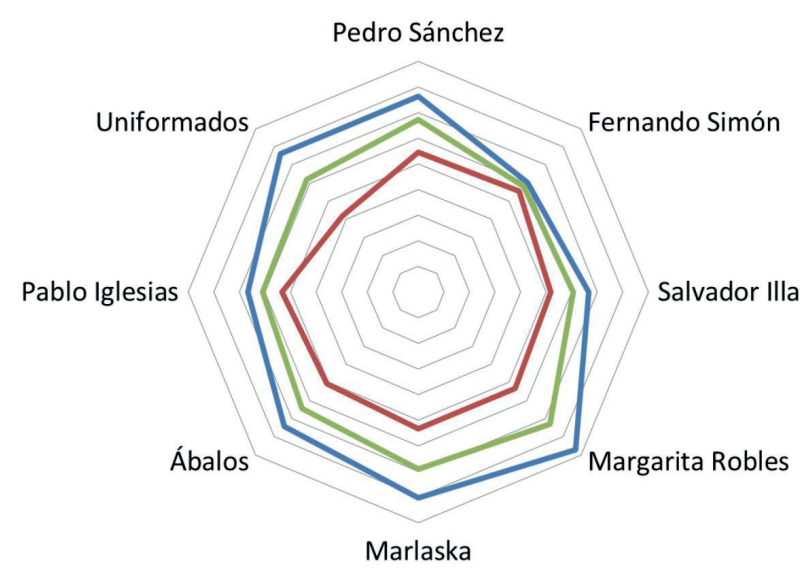

Gráfico 1. Resultados obtenidos por los portavoces (medias sobre 10)

Tabla 6. Resultados obtenidos por los portavoces (medias sobre 100)

\begin{tabular}{|l|c|c|c|c|c|c|c|}
\hline \multicolumn{1}{|c|}{$\begin{array}{c}\text { Categoría } \\
\text { (medias) }\end{array}$} & $\begin{array}{c}\text { Pedro } \\
\text { Sánchez }\end{array}$ & $\begin{array}{c}\text { Fernando } \\
\text { Simón }\end{array}$ & Salvador Illa & $\begin{array}{c}\text { Margarita } \\
\text { Robles }\end{array}$ & $\begin{array}{c}\text { Fernando } \\
\text { Grande-Mar- } \\
\text { laska }\end{array}$ & $\begin{array}{c}\text { José Luis } \\
\text { Ábalos }\end{array}$ & $\begin{array}{c}\text { Pablo } \\
\text { Iglesias }\end{array}$ \\
\hline Micro-análisis & 76,19 & 60,32 & 66,67 & 86,90 & 80,27 & 74,29 \\
\hline Narrativa & 54,55 & 55,56 & 51,67 & 53,33 & 53,33 & 50,67 & 53,33 \\
\hline $\begin{array}{l}\text { Media del } \\
\text { portavoz }\end{array}$ & 67,17 & 58,33 & 60,42 & 72,92 & 69,05 & 64,44 \\
\hline
\end{tabular}

En paralelo a las comparecencias ministeriales, se celebraron ruedas de prensa del Comité de Gestión Técnica del coronavirus Covid-19, de la mano de Fernando Simón (director del Centro de Coordinación de Alertas y Emergencias Sanitaria), quien, a pesar de haber contraído el virus, ha tenido una presencia televisual constante, ya sea presentando datos de la pandemia, contestando a las preguntas de periodistas o, incluso, arrogándose funciones alejadas de la labor de un funcionario como arropar al general jefe del Estado Mayor de la Guardia Civil tras la asunción de las fake news por el instituto armado.

Tabla 7. Fernando Simón (datos en \%)

\begin{tabular}{|c|c|c|c|c|c|c|c|}
\hline \multicolumn{3}{|c|}{ Total comparecencias analizadas $=9$} & $0=$ nada & $1=$ poco & 2 = bastante & $3=$ mucho & Resultados \\
\hline \multirow{7}{*}{$\begin{array}{l}\text { La comunicación } \\
\text { en la escena (mi- } \\
\text { cro-análisis) }\end{array}$} & 1 & Auctoritas & 0,00 & 0,00 & 0,00 & 100,00 & 100,00 \\
\hline & 2 & Empatía & 77,78 & 22,22 & 0,00 & 0,00 & 7,41 \\
\hline & 3 & Capacidad de divulgación & 0,00 & 77,78 & 22,22 & 0,00 & 40,74 \\
\hline & 4 & Capacidad de síntesis y de exposición & 0,00 & 0,00 & 100,00 & 0,00 & 66,67 \\
\hline & 5 & Uso de datos & 0,00 & 0,00 & 0,00 & 100,00 & 100,00 \\
\hline & 6 & Autocontrol y discreción & 0,00 & 0,00 & 0,00 & 100,00 & 100,00 \\
\hline & 7 & Ritual escénico & 77,78 & 22,22 & 0,00 & 0,00 & 7,41 \\
\hline \multirow{5}{*}{$\begin{array}{l}\text { Categoría } \\
\text { narrativa }\end{array}$} & 8 & Confusión y opacidad & 100,00 & 0,00 & 0,00 & 0,00 & 0,00 \\
\hline & 9 & Transparencia & 0,00 & 0,00 & 100,00 & 0,00 & 66,67 \\
\hline & 10 & Duración del discurso & 0,00 & 0,00 & 0,00 & 100,00 & 100,00 \\
\hline & 11 & Narración & 0,00 & 77,78 & 22,22 & 0,00 & 40,74 \\
\hline & 12 & Información de servicio & 0,00 & 0,00 & 88,89 & 11,11 & 70,37 \\
\hline & & & & & & Media & 58,33 \\
\hline
\end{tabular}

El análisis sincrónico de las intervenciones de Fernando Simón reporta una media de un 58,33/100. En sentido positivo, su auctoritas, el uso de datos, la ausencia de confusión o su autocontrol y discreción reportan resultados máximos. Sus principales falencias se concentran en variables como la empatía, la narración o el ritual escénico -items evaluados siempre de acuerdo a los cánones establecidos para el estudio (ver 4.1.)-. Las fortalezas y las debilidades no sorprenden en relación al rol que, en este caso, juega un técnico de su naturaleza. 
El caso de Simón es también paradigmático porque la vestimenta y la caracterización de un portavoz -deliberada o no- cumple una función específica como elemento articulador del significado. El personaje pretende alejarse del encorsetado engranaje político y mostrarse más cercano a la audiencia. Ese matiz diferenciador se enfatiza con sus rasgos físicos y el lenguaje de su vestimenta (jersey, rebeca, camisa de manga corta), estética y kinésica. De esta manera, y visto de una manera diacrónica, las contradicciones importantes que tuvo a lo largo de sus disertaciones podrían pasar a un segundo plano. Por otra parte, Fernando Simón fue erigido el científico de referencia del Gobierno, y, en ese papel ha marcado los tempos de todas

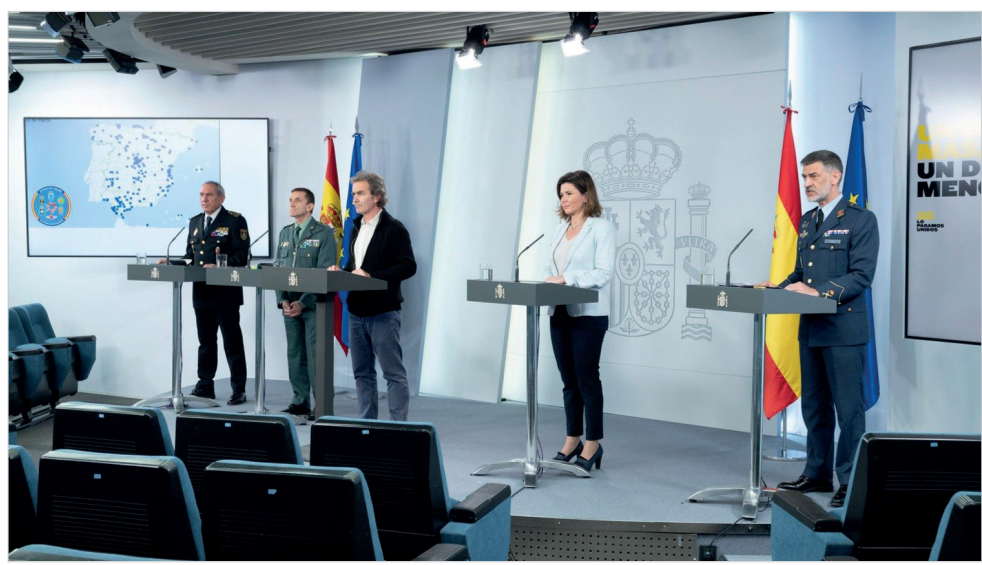

Figura 1. Rueda de prensa telemática tras la reunión del Comité de Gestión Técnica del Coronavirus. Ref.: Pool Moncloa / Borja Puig de la Bellacasa.

https://www.elconfidencialdigital.com/content/print/pablo-iglesias-consiguiouniformados-dejaran-comparecer-ruedas-prensa-moncloa/20200430171442143982

las intervenciones del Comité de Gestión

Técnica del Coronavirus y, más tarde, de la Comisión Técnica de la Desescalada, así como en la interpretación de las cifras diarias de infectados o muertos, en un papel más propio de un ministro de Sanidad que de uno de los funcionarios a su cargo. La teoría indicaría, en este caso, que un funcionario del Estado, inmerso en una función de portavocía, debería haberse movido siempre en un campo semántico que circulase por las marcas de una cierta asepsia funcionarial. Y la asunción de otros roles más gubernamentales ha podido mermar su credibilidad y competencia técnica (Zarzalejos, 2020). Así, se ha detectado como, a partir del 21 de abril de 2020, se percibe un desgaste evidente en su imagen, y a medida que transcurre la pandemia y se pasa de una a otra fase, su concurso se vuelve cada vez más redundante y prescindible.

En todo el entramado de portavoces, quedarían finalmente por mencionar las comparecencias diarias de las 12:30 horas, que fueron sufriendo una clara evolución en el tiempo. En ellas, el Gobierno apostó por una puesta en escena diferente. A Fernando Simón y a la Secretaria General de Transportes, María José Rallo, se les unieron, a partir del 20 de marzo de 2020, los "uniformados" (tabla 2). Los representantes de las fuerzas y cuerpos de seguridad del Estado, que formaban parte del Comité de Gestión Técnica, jugaron un papel claramente informativo. Dada la naturaleza de su profesión, la rigidez y el sentido de la disciplina que mostraron en sus intervenciones derivaron en valoraciones máximas en variables como el autocontrol y la discreción, el ritual escénico, la capacidad de síntesis, la ausencia de confusión o la auctoritas. Suspenden en capacidad empática y variables como la estructura narrativa o la transparencia.

Ahora bien, ese segundo plano en lo mediático se rompió el día 25 de abril, día en el que también Pedro Sánchez habló por primera vez -según los vídeos analizados en la muestra- del desconfinamiento parcial. Tras una polémica intervención del jefe del Estado Mayor de la Guardia Civil sobre el seguimiento de bulos mediáticos contrarios al Gobierno, se decidió poner fin a estas intervenciones diarias que ocupaban una parte notable del day time televisivo y reforzaban las metáforas de guerra esgrimidas por el Gobierno. Obviamente, ninguno de los miembros de los tres cuerpos armados contaba con la suficiente experiencia en estos asuntos y, aunque se desconoce su media training, seguramente no fue muy extenso. Como indica la presidenta de Atrevia, Vilanova (2018), a los portavoces mediáticos les corresponde un papel que va más allá de una entrevista o una rueda de prensa puntual y deben asumir que estas tareas requieren dedicación, disponibilidad y renovación constante. Además, como señalan Costa-Sánchez y López-García (2020, p. 10),

"la fórmula y discurso de portavocía aplicada resulta contraria a las recomendaciones de comunicación de riesgos y de crisis. De hecho, supone una novedad respecto a situaciones anteriores, por la elevada cantidad de voces oficiales".

\subsection{Disección y correlatos de la comunicación de crisis Covid-19}

En todo manejo de comunicación de crisis que se precie, su máximo responsable diseña siempre un "sistema de alianzas", no solamente con medios y grupos de comunicación sino también con todo tipo de stakeholders. Su misión es hacer de muro de contención y ayudar a contrarrestar los ataques que se puedan sufrir. En este caso concreto, la teoría indica que no se puede abordar un plan de crisis teniendo en contra a importantes medios de comunicación y a una parte importante de colectivos profesionales como los sanitarios. Parece, no obstante, que, si bien pueden entreverse algunas alianzas claras con ciertos media, no se ha observado ese mismo trabajo con colectivos vitales en la crisis: sanitarios, investigadores, científicos o líderes de comunidades de diferente índole.

Por otro lado, la comunicación en redes sociales parece que no ha conseguido destronar o imponerse-al menos durante los meses críticos de marzo y abril- a la comunicación de carácter convencional, liderada por las televisiones generalistas y en abierto. Así, el peso de la comunicación del Gobierno, sin descuidar ningún medio de comunicación, se ha volcado en la televisión, y, en esta labor, el presidente del Gobierno y los portavoces habituales tuvieron un papel determinante. 
En cuanto a las notas obtenidas sobre 10 , la calificación media de todos los portavoces analizados en este estudio fue de un $6,44 / 10$, lo que no puede considerarse como un óptimo resultado comunicativo. Pese a identificarse notorias diferencias entre ellos, existe un grado de desviación poco pronunciado entre los sujetos analizados, o, lo que es lo mismo, cierta homogeneidad en sus habilidades comunicativas -o falta de ellas- en el período analizado.

Así, y como muestra la tabla 6, Fernando Simón es el portavoz peor valorado, y le siguen Salvador Illa, Pablo Iglesias, José Luis Ábalos y los "uniformados". Pedro Sánchez ocupa una posición discreta, mientras que los mejor valorados son la ministra Robles y el ministro Grande Marlaska alcanzando, la primera el notable, y rozándolo el ministro del Interior.

En cualquier caso, y en tiempos del argoTrump, en el que son habituales las intervenciones cortas de algunos líderes mundiales -como la alemana Angela Merkel-, que acostumbran a fijar muy bien las ideas-fuer-

za y ofrecen titulares claros en unos cinco minutos de comparecencia, las intervenciones del presidente del Gobierno español iban en sentido contrario: eran muy extensas, y sin atender a una estructura convencional en la que primero se establece el marco: asuntos importantes a desarrollar, jerarquizándolos por orden de importancia y primando lo novedoso para marcar la agenda mediática. Y lo mismo sucedió con la mayor parte de las intervenciones del ministro de Sanidad, que nunca se desviaron de un tono burocrático (deliberado o no), puesto que los titulares para los medios de comunicación eran de uso exclusivo del presidente Sánchez.

De ahí que el peligro de generar cierta cacofonía gubernamental no fuese tanto cometer, o no, muchos errores - dentro de los márgenes de transparencia habitual-, sino más bien la posibilidad de no llegar a esgrimir un comportamiento honesto que permita conservar y afianzar la confianza que los ciudadanos de un país -atenazados por el miedo- hayan podido depositar en un Gobierno y sus líderes. Ahora bien, la comunicación de una organización puede entrar también en una espiral mediática negativa, puesto que una crisis suele exacerbar las relaciones y las pasiones (Riom; Libaert; Adary, 2010).

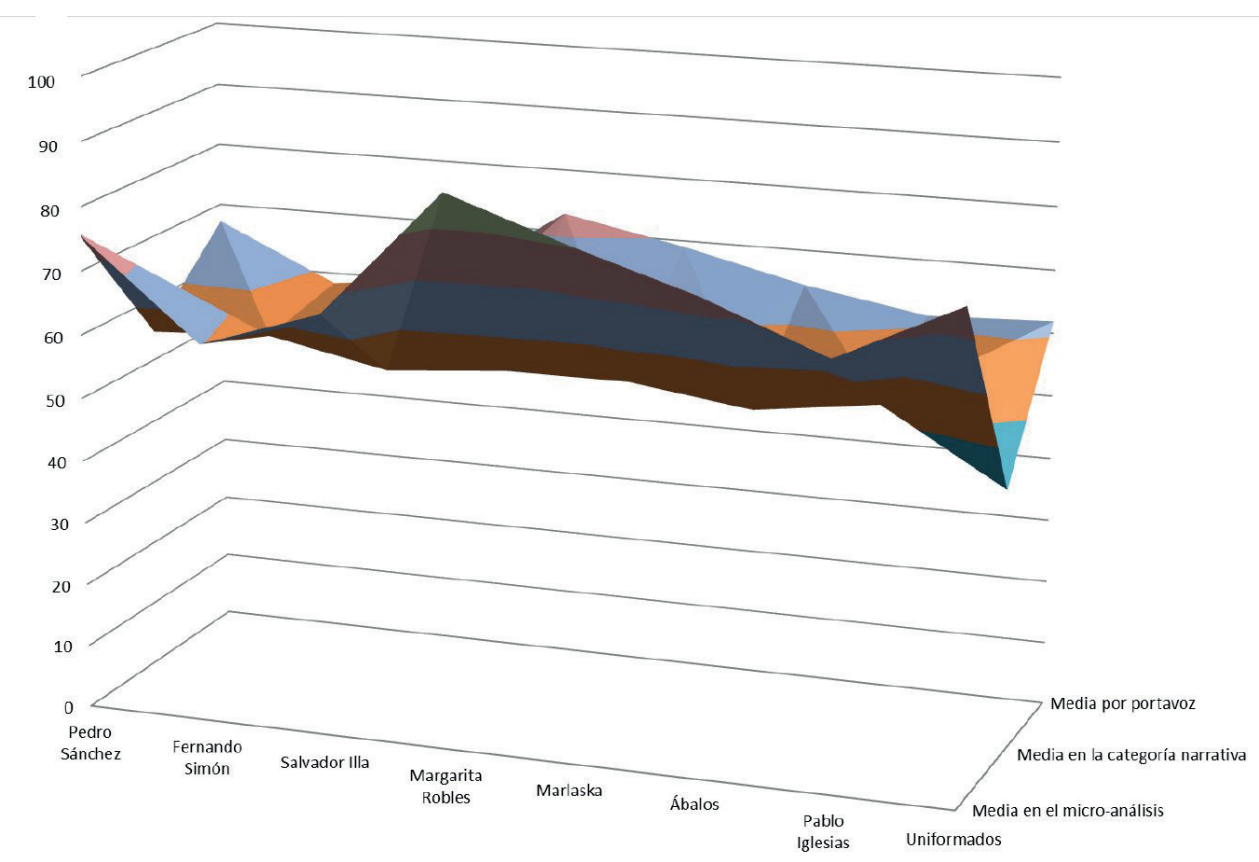

Gráfico 3. Representación gráfica del rol del portavoz y la comunicación de crisis en la pandemia Covid-19 en España 


\subsection{Inferencias en la estrategia audiovisual}

El formato de rueda de prensa diaria y su correspondiente puesta en escena carecería de repercusión mediática si no se apoyase en la televisión generalista y en abierto, así como en un público "cautivo" y ávido de noticias. En este sentido, habría que tener en cuenta que una crisis que desborda el marco sanitario e invade el terreno socio-económico, jurídico, logístico y hasta psicológico, puede gozar de una enorme difusión informativa, con tratamientos de espectacularización mediática, como un recurso ineludible de ciertos formatos y contenidos televisivos (Pellisser; Pineda, 2014). Y, en este terreno, se mueve con una amplia soltura la televisión generalista, tanto en sus programas informativos como en todo tipo de magazines (caso evidente del programa "Sálvame", que alcanzó elevadas audiencias, cercanas a los tres millones). Pero la televisión broadcasting -como ya había señalado López-Villanueva (2011, p. 9)-

"no está muerta ni agoniza, tan solo entra de forma sucesiva en nuevas fases, sin que desaparezcan muchos elementos del pasado".

Se cumple, por tanto, el axioma de que, en situaciones de alarma sanitaria, buena parte de la información proviene de los mass media (Lovrey et al., 2006). En este contexto, los medios de comunicación son determinantes en la construcción de la comunicación de riesgos sanitarios ( $\mathbf{M a}, 2005)$ y la cobertura que hacen de los acontecimientos es un poderoso factor para determinar las reacciones que se perciben en una crisis de esta magnitud (Glik, 2007).

Cabe reseñar, además, que durante el mes de marzo la cobertura de las televisiones generalistas (Barlovento Comunicación, 2020a) alcanzó un récord de consumo histórico mensual: el tiempo diario por espectador sobre la cobertura diaria fue de 6 horas 11 minutos (+65\% respecto a 2019), y el "minuto de oro" para La sexta noticias el 14 de marzo con el 35,9\% de la audiencia total. En cuanto al mes de abril (Barlovento Comunicación, 2020b) marcó un nuevo récord histórico mensual del consumo televisivo con 302 minutos por persona y día, y la suma de las audiencias de $L a 1, A 3, T 5, L a$ sexta y Cuatro supuso el 50,5\% de la audiencia televisiva.

Por otro lado, se ha originado un nuevo fenómeno de alcance mundial y propio también de los tiempos de coronavirus: el desplazamiento de una parte importante de la audiencia del prime time al day time (AlphonsoTV, 2020). Aunque, en España, Barlovento Comunicación sitúa -al igual que AlphonsoTV en EUA- el prime time como el dominante, el análisis de la consultora norteamericana indica que los incrementos de las audiencias EUA en la televisión de cable y en la generalista provienen de los programas de primera hora de la mañana y de la franja horaria matinal. De ahí que las comparecencias de portavoces en España se extendiesen desde las 12 a las 15:30 horas, con momentos álgidos a partir de las 15 horas. Tanto el Comité de Gestión Técnica como el presidente del Gobierno han intervenido en estas franjas horarias con resultados óptimos de audiencia, y en algunos casos invadiendo la franja del telediario de $L a 1$.

Como hipótesis de trabajo, parece que estas intervenciones en day time guardan una estrecha relación con los hábitos de ocio de la clase media en tiempos de pandemia, muy inclinados en el prime time a ver contenidos exclusivos, en vista de los elevados consumos de la TV generalista y de las plataformas de streaming (además de videojuegos y e-sports) detectados por Telefónica; por no hablar del auge de las televisiones temáticas de pago, que, según Barlovento, desde agosto del año 2007 tuvieron en el mes de abril su mejor dato desde entonces. Recordemos que Movistar anunció que en el primer fin de semana del confinamiento se alcanzó el máximo anual de espectadores que accedían a la plataforma, con un incremento diario del 8\%, mientras que el consumo de VoD creció un 72\% durante el primer fin de semana de confinamiento y los volúmenes de tráfico de Netflix -con datos de Movistar-aumentaron en una semana entre el 54\% y el 75\% (Juste; Galera, 2020).

Como se ha podido ver, el marco o el framing de la estrategia comunicativa fue establecido por el Gobierno de la nación. La permanencia obligatoria de la población en sus casas modificó modelos y tiempos de ocio. Diariamente, una buena parte de los españoles se informaban de lo que estaba sucediendo en tiempo real, no solo por las redes sociales, sino también por el resto de medios convencionales, entre los que la televisión generalista fue decisiva. Más del $90 \%$ de los televidentes -según una encuesta de 40dB.es para el diario El país (19/4/2020, p. 12)- conectaban varias veces al día con programas televisivos -y no solamente informativos- para conocer las novedades que se iban produciendo. De esta manera se llegaron a alcanzar audiencias ya no solo impropias de una comparecencia gubernamental, sino de un horario de day time de las 15 horas.

La primera rueda de prensa del presidente del Gobierno tras el confinamiento (14 de marzo de 2020) contó con una audiencia media de 18 millones de espectadores (y cerca de 22 millones de cobertura), con un 80,9\% de cuota de pantalla y fue la más vista en la historia de nuestra televisión desde la llegada de las televisiones privadas. Son cifras con las que solamente puede competir la selección española de fútbol, que tuvo su emisión más exitosa en la Eurocopa 2008 con 15,3 millones de espectadores y una cuota del $77,5 \%$, seguida del España-Rusia del Mundial de Rusia, que concitó ante las pantallas a casi 15 millones de espectadores, con una cuota de pantalla del 81,1\% (Barlovento Comunicación, 2018, p. 20). A partir de aquí, el interés por las apariciones del presidente disminuiría. El siguiente fin de semana, 21 y 22 de marzo, y en horarios

La nota media de los portavoces de la crisis del coronavirus es de un aprobado alto, incluido el propio presidente del Gobierno, y solo la ministra Robles ha conseguido una calificación de notable. En su conjunto, estas actuaciones no pueden considerarse como un óptimo resultado comunicativo 
de day y prime time, se consiguieron 13,7 millones de espectadores de media en sábado y cerca de 10 millones el domingo. Y en el tercer fin de semana de confinamiento -el sábado, 28 de marzo- la audiencia descendió a 8,8 millones.

Durante el mes de abril, las audiencias fueron también importantes. En plena Semana Santa, el 12 de abril la audiencia superó los 8 millones. Y la del sábado, 18 de abril, fue de 6,3 millones de espectadores, con un 37,8\% de la audiencia; y el 25 de abril la comparecencia del presidente, emitida a las 20:15 horas por Telecinco, llegó a ser el programa más visto del día con 3.020.000 espectadores de audiencia media y casi el $20 \%$ de cuota de pantalla.

Por tanto, creemos que, a pesar del significativo descenso de audiencias en cada comparecencia, hay que valorar las cifras globales. Es imposible para cualquier gobernante, e incluso para el mayor influencer televisivo, mantener una audiencia media de 10 a 18 millones. Si cuantificamos las audiencias acumuladas alcanzadas durante los meses de marzo y abril llegamos a la conclusión de que el presidente del Gobierno alcanzó alrededor de 130 millones de espectadores durante ese período de tiempo, cifras que hablan a las claras del impacto mediático obtenido.

\section{Conclusiones}

Pormenorizadamente, las conclusiones de este trabajo son las siguientes:

1. La estrategia del Gobierno de concentrar buena parte de sus recursos, así como de pivotar su estrategia comunicativa, en la comparecencia de portavoces gubernamentales en la televisión generalista y en abierto, se ha revelado eficaz en la medida en la que se ha producido una elevada concentración informativa de voces amigas, con datos históricos de audiencia y ocupación de espacios informativos sin parangón en un estado moderno. Otra cosa distinta es valorar, cualitativamente, la capacidad de convicción de los portavoces utilizados, así como su eficacia. Del mismo modo, es innegable el impacto mediático de todas estas intervenciones durante los meses de marzo y abril. El presidente del Gobierno, logró una audiencia de más 130 millones de personas durante este período de tiempo. A esta audiencia habría que sumarle también la conseguida por el resto de portavoces gubernamentales, con lo cual se alcanzarían cifras superiores a los 200 millones. Unos datos muy difíciles de conseguir por ningún líder de un país democrático y su gobierno en una situación que no pudiera calificarse como "excepcional". Además, habría que contabilizar la invasión, en numerosas ocasiones, de los tiempos específicos de los telediarios de las 14 a 15 horas, fundamentalmente los de TVE 1 y el Canal 24 Horas, pero también los de La sexta, así como la ocupación de tiempos y espacios clave televisivos que, de esta forma, les eran arrebatados a la oposición. Y ello al margen de la mayor o menor calidad de las intervenciones de los portavoces que han sido ya analizadas y calificadas.

2. La política de portavocía gubernamental involucrando al presidente, vicepresidentes, ministros, secretarios generales, altos cargos de policía, guardia civil y ejército, y coordinadores varios llegó a utilizar un amplio casting de casi 30 personas. En su conjunto, con desiguales dotes actoriales; muy diferente training en cuestiones de comunicación y, a veces, en situaciones que rayaban en la cacafonía. Una situación extraordinariamente comprometida, aunque no nueva en cuestiones de portavocía. Cuando Cronkite (1996, p. 326) habla en sus memorias de la cobertura de la guerra del Vietnam hace hincapié en una situación de crisis poco habitual que podría aplicarse hoy día:

"Yo no estaba preparado para admitir la verdad: que aquellos desventurados portavoces tenían por misión explicar una guerra que no tenía explicación, y que tanto ellos como la prensa eran conscientes de que aquella era la aterradora verdad".

3. Aunque las notas conseguidas por la mayor parte de estos portavoces no puedan calificarse de elevadas (puesto que solamente la ministra Robles ha conseguido una calificación de notable), sí han tenido ciertos logros, porque han permitido mostrar en numerosas ocasiones la labor de equipo del Gobierno. Ahora bien, estos logros han estado algo atenuados por los tonos monocordes y burocráticos, la falta de empatía o la exagerada duración de muchas de las intervenciones. La excepción a este tono general, fue la utilización de estrategias macrodiscursivas ("la mejor sanidad del mundo", "el octavo país de la OCDE en número de tests realizados"), que amenazaron por socavar los discursos gubernamentales al darse de bruces con la realidad.

4. La abundante utilización de conferencias de prensa y de portavoces mediáticos, inmersos en varios decorados televisivos (con mesas y atriles; en grupos, en dúos o en solitario) y las dificultades de "guionizar" las intervenciones de tan extenso colectivo, a veces en comparecencias que podrían durar en day time de 12:30 a 15:30 horas, originaron en algunos momentos cierto caos narrativo. A las dificultades de guionización para tan extenso periodo de tiempo (hubiera hecho falta, además de un equipo de guionistas más experimentado, los recursos humanos de una productora) y de realizar un training efectivo con tan elevado número de portavoces, se le unieron los condicionantes de tan compleja puesta en escena. Estos condicionantes se traducían en apelar a la resolución de los problemas por vías políticas, aunque se tratasen de los

La estrategia del Gobierno de pivotar su acción comunicativa en la comparecencia de portavoces gubernamentales en la televisión generalista se ha revelado eficaz en la medida en la que se ha producido una elevada concentración informativa de voces amigas, con datos históricos de audiencia y ocupación de espacios informativos sin parangón en un estado moderno 
clásicos dominios de una crisis: técnicos, económicos, legales y éticos. La insistencia en esta estrategia de carácter más político, y cada vez más alejada del campo de las relaciones públicas, acabó por agotar muchas de las elecciones narrativas posibles, e incluso por vaciar de sentido las intervenciones de algunos de los portavoces más destacados de la pandemia.

5. La Covid-19 ha vuelto a poner en valor, sorprendiendo a numerosos líderes de opinión, y no solo en España, los recursos informativos de las televisiones en abierto, en detrimento evidente de la prensa (nativos digitales incluidos) e incluso de la radio. Abundando en esta cuestión, y como ya había analizado en Estados Unidos la consultora de medios AlphonsoTV (2020), la pandemia incrementó también las audiencias de los informativos de cable (pay TV) y de los canales locales. En España, sin embargo, con una pobre red local y sin canales específicos de noticias en la televisión de pago, han reinado Antena 3, La sexta (el canal más visto algunos días) y Telecinco (tanto en informativos como en magazines). Muchos estrategas mediáticos se han sorprendido, sin embargo, por este renacimiento de la televisión generalista, creyendo que este tiempo podría ser más propicio a la sabiduría de la multitud que a la dictadura de los expertos, como así parece que ha sido.

6. En el ámbito de la comunicación corporativa, hubiéramos apostado por un plan de comunicación que primase la información de servicio -como la proporcionada por la Ofcom británica (2020), enseñando a distinguir los hechos de las fake news- y que reclamase el decidido apoyo de las comunidades autónomas, ayuntamientos, agentes sociales y diferentes organizaciones civiles. El éxito de un buen confinamiento y de una correcta fase de desescalada debería de haber involucrado a esos millones de stakeholders, que son el conjunto de españoles y sus organizaciones más representativas. No ha existido tampoco una comunicación específicamente "sanitaria" ni una comunicación ligada a "catástrofes", y el grueso de la artillería mediática se focalizó en el recurso continuo a las conferencias de prensa, que aun siendo muy numerosas no garantizan per se una mayor transparencia ni aumentan los niveles de credibilidad, a no ser que se ofrezcan en cada una de ellas nuevos puntos de vista.

7. Contra lo que muchos analistas tal vez esperaban, en las comparecencias públicas de los portavoces gubernamentales no ha habido -durante el período de tiempo analizado- cabida para las historias, que son -como indican los expertos en storytelling- instrumentos naturales de generación de empatía. Y, aunque de un análisis de contenido de las intervenciones realizadas se puedan extraer diferentes líneas argumentales (datos, aclaraciones, declaración de intenciones, consejos, justificaciones...), la narración, el relato en sí, no era en este caso la clave del discurso. Tal vez por la situación excepcional que se vivía o por la primacía de la comunicación política sobre la estrictamente corporativa.

8. Esta primacía de la política sobre la comunicación corporativa, nos indica también, como sostiene Salmon (2019, pp. 55-56), que ya no estamos inmersos en los tiempos del relato, que supone dominar la agenda y construir secuencias coherentes, sino que ahora se impone la lógica del enfrentamiento permanente en todos los partidos del arco parlamentario; una estrategia que acaba devorando la narración en la política. Y como también indica Greenberg (2017), hace ya algún tiempo que los consultores políticos (spin doctors) no solamente han tomado el control de la política estadounidense, sino que también han extendido su influencia a expertos de diferentes países. En el caso de España, los spin doctors han acabado por controlar también a los pundits (directores de comunicación), que ahora trabajan para ellos. Las consecuencias de esta transformación están todavía por definir, pero al menos dos cosas están claras: han modificado sustancialmente los principios estratégicos por los que se regía la comunicación de crisis, ahora enfrentada al caos narrativo. Y, en segundo lugar, han primado la utilización de resortes políticos para la resolución de las crisis, abandonando tareas más propias de comunicadores, como la información de servicio, la relación estrecha con todo tipo de media o los actos de relaciones públicas como eje primordial de la comunicación.

\section{Referencias}

Alphonso (2020). Is daytime becoming the new prime time. 7 April. https://bit.ly/2ZzhBo7

Álvarez, Tomás; Caballero, Mercedes (1997). Vendedores de imagen. Barcelona: Paidós. ISBN: 8449303702

APM (2019). Informe anual de la profesión periodística. Madrid: APM.

Arceo-Vacas, Alfredo (2012). “El portavoz en la comunicación de las organizaciones”. En: Arceo, A. (coord.). El portavoz en la comunicación de las organizaciones. Fundamentos teórico-prácticos. Alicante: Universidad de Alicante, pp. 47-51. ISBN: 9788497172295

Arroyo, Luis; Yus, Magali (2011): Los cien errores en la comunicación de las organizaciones. Madrid: ESIC. ISBN: 97884 73564939

Barlovento Comunicación (2018). La audiencia de los mundiales de fútbol. https://www.barloventocomunicacion.es/wp-content/uploads/2018/07/Informe_Barlovento_Mundial_Futbol_mundial_ rusia_2018.pdf

Barlovento Comunicación (2020a). Audiencias mensuales marzo 2020.

https://www.barloventocomunicacion.es/audiencias-mensuales/analisis-audiencias-tv-marzo-2020

Barlovento Comunicación (2020b). Audiencias mensuales abril 2020.

https://www.barloventocomunicacion.es/audiencias-mensuales/analisis-audiencias-tv-abril-2020-2 
Barquero, José-Daniel; Barquero, Mario (2010). Marketing relacional y comunicación para situaciones de crisis. Barcelona: Profit Editorial. ISSN: 9788492956081

Berceruelo, Benito (2016). Comunicación empresarial. Madrid: Estudio de Comunicación. ISBN: 9788461773879

Burke, Kenneth (1969). A rhetoric of motives. California: University of California Press. California. ISBN: 9780520015463 Camacho-Marquina, Idoia (2017). Formación de portavoces. Barcelona: UOC. ISBN: 9788491167280

Capriotti-Peri, Paul (2005). "La gestión comunicativa en situaciones de crisis”. En: Castillo-Esparcia, A. (coord.). Comunicación organizacional. Teorías y estudios. Málaga: Clave Aynadamar. ISBN: 8480749504

Carmona, Ramón (2002). Cómo se comenta un texto fílmico. Madrid: Cátedra, 5a ed. ISBN: 8437609631

Carrascosa, José-Luis (2003). Comunicación. De la Sociedad de la Información a la Sociedad de la Comunicación. Madrid: Ediciones Arcadia.

Casero-Ripollés, Andreu (2020). "Impact of Covid-19 on the media system. Communicative and democratic consequences of news consumption during the outbreak". El profesional de la información, v. 29, n. 2, e290223.

https://doi.org/10.3145/epi.2020.mar.23

Cervera-Fantoni, Ángel-Luis (2004). Comunicación total. Madrid: ESIC. ISBN: 8473563867

Coombs, W. Timothy (2015). Ongoing crisis communication. London: Sage. ISBN: 9781544331959

Coombs, W. Timothy; Holladay, Sherry J. (2012). The handbook of crisis communication. Oxford: Wiley \& Blackwell. ISBN: 9781405194419

Costa-Sánchez, Carmen; López-García, Xosé (2020). “Comunicación y crisis del coronavirus en España. Primeras lecciones". El profesional de la información, v. 29, n. 3, e290304.

https://doi.org/10.3145/epi.2020.may.04

Cronkite, Walter (1996). Memorias de un reportero. Madrid: El País/Aguilar. ISBN: 8403596006

De-la-Cierva, Yago (2009). "La comunicación en tiempos de crisis”. En: Mora, J. M. (ed.): 10 ensayos de comunicación institucional. Pamplona: Eunsa. ISBN: 9788431326180

Fearn-Banks, Kathleen (2017). Crise communications. A casebook approach, $5^{\text {th }}$ ed. New York: Routledge. ISBN: 9781315684857

Fita, Jaume (2004). “Comunicación de crisis”. En: Losada Díaz, J. C. (coord.): Gestión de la comunicación en las organizaciones. Barcelona: Ariel, pp. 193-216. ISBN: 8434413035

García-Santamaría, José-Vicente (2019). Las nuevas fronteras de la comunicación corporativa. Barcelona: UOC. ISBN: 9788491806615

Glik, Deborah C. (2007). "Risk communication for public health emergencies". Annual review of public health, n. 28, pp. 33-54. https://doi.org/10.1146/annurev.pub/health.28.021406.144123

Greenberg, David (2017). Republic of spin: An inside history of the American presidency. W Norton\&Company.

Heath, Robert L. (2004). "Telling a story: A narrative approach to communication during crisis". In: Millar, Dan P. \& Heath, Robert L. (eds.). Responding to crisis. A rhetorical approach to crisis communication, pp. 167-187. New Jersey: Laurence Erlbaum. ISBN: 0805840605

Holmes, Bev J.; Henrich, Natalie; Hancock, Sara; Lestou, Valia (2009). “Communicating with the public during health crises: experts' experiences and opinions". Journal of risk research, v. 12, n. 6, pp. 793-807. https://doi.org/10.1080/13669870802648486

Juste, Marta; Galera, César (2020). “El consumo de televisión en España bate su récord histórico en la primera semana de confinamiento". Expansión, 23 marzo.

https://www.expansion.com/economia-digital/2020/03/23/5e74e31a468aeb92708b45d3.html

Kerlinger, Fred; Lee, Howard B. (2002). Investigación del comportamiento. México: McGraw Hill / Interamericana. ISBN: 9789701030707

La Moncloa (2020). Vídeos.

https://www.lamoncloa.gob.es/multimedia/videos/Paginas/index.aspx?mts=202003

Libaert, Thierry (2010). La communication de crise, $3^{\mathrm{me}}$ ed. Paris: Dunod. ISBN: 9782100549443

López-Tello, Enrique (2006). “Comunicación de crisis: el valor de la anticipación”. Comunicas. Revista de tendencias en comunicación, n. 6, pp. 6-9.

López-Villanueva, Javier (2011). “La reconfiguración de la cadena de valor”. En: Álvarez-Monzoncillo, José-María (coord.). La televisión etiquetada: nuevas audiencias, nuevos negocios. Barcelona: Ariel/Fundación Telefónica. ISBN: 9788408098706 
Losada-Díaz, José-Carlos (2018). (No crisis) La comunicación de crisis en un mundo conectado. Barcelona: UOC. ISBN: 9788491801436

Lowrey, Wilson; Gower, Karla; Evans, William; MacKay, Jenn (2006). “Assessing newspaper preparedness for public health emergencies". Journalism and mass communication quarterly, n. 83, pp. 362-380.

Ma, Ringo (2005). "Media crisis and SARS: An introduction”. Asian journal of communication, n. 15, pp. $241-246$. https://doi.org/10.1080/01292980500260656

Marzal-Felici, Javier; Gómez-Tarín, F. Javier (2007). “Interpretar un film. Reflexiones en torno a las metodologías de análisis del texto fílmico para la formulación de una propuesta de trabajo". En: Marzal Felici, Javier; Gómez Tarín, F. Javier. Metodologías de análisis del film. Madrid: Editorial Edipo, pp. 31-56. ISBN: 9788488365200

Ofcom (2020). "Cutting through the Covid-19 confusion". Ofcom.

https://www.ofcom.org.uk/research-and-data/media-literacy-research/coronavirus-resources

Paniagua-Gallart, Carlos (2004). "La gestión de la comunicación en situaciones de crisis". En: Bel Mallén, José Ignacio (coord.). Comunicar para crear valor. Pamplona: Eunsa. ISBN: 8431321660

Pellisser-Rossell, Nel·lo; Pineda, Antonio (2014). “Información política televisiva y espectacularización: un análisis comparativo de programas informativos y de infoentretenimiento". Estudios sobre el mensaje periodístico, v. 20, n. 2, pp. 821-839.

https://doi.org/10.5209/rev_esmp.2014.v20.n2.47036

Ramírez-de-la-Piscina, Txema (2007). Formación de portavoces. Los movimientos sociales ante la esfera pública. Barcelona: Bosch. ISBN: 9788497902892

Riom, Aude; Libaert, Thierry; Adary, Assäe (2010). Communication: Toute la fonction. Paris: Dunod. ISBN: 978210 0543915

Rodríguez-Andrés, Roberto (2011). "La efectividad del uso del miedo como factor persuasivo en la comunicación de riesgo en las crisis sanitarias". Revista de comunicación y salud, v. 1, n. 2, pp. 33-46.

Rosillo, Fran (2018). Clases Máster comunicación corporativa, UC3M.

Salmon, Christian (2019). La era del enfrentamiento. Barcelona: Península. ISBN: 9788499428567

Sartre, Véronique (2008). La communication de crise. Paris: Les Éditions Demos. ISBN: 2910157857

Seeger, Matthew W. (2007). "Best practices in crisis communication: An expert panel process". Journal of applied communication research, v. 34, n. 3, pp. 232-244.

https://doi.org/10.1080/00909880600769944

Seeger, Matthew W.; Sellnow, Timothy L.; Ulmer, Robert D. (2003). Communication and organizational crisis. Westport, C.T.: Praeger. ISBN: 1567205348

Sellnow, Thimothy L.; Seeger, Matthews M. (2013). Theorizing crisis communication. Oxford: John Wiley \& Sons. ISBN: 9780470659304

Taylor, Maureen; Kent, Michael L. (2007). "Taxonomy of mediated crisis response". Public relation review, n. 33, pp. 140-146.

https://doi.org/10.1016/j.pubrev.2006.11.017

Túñez, Miguel (coord.) (2007). Comunicación preventiva. Planificación y ejecución de estrategias de información interna y externa ante situaciones de crisis. A Coruña: Netbiblo. ISBN: 9788497450607

Túñez, Miguel (2012). La gestión de comunicación en las organizaciones. Zamora: Comunicación Social. ISBN: 97884 92860944

Vilanova, Nuria (2018). Las claves de un buen portavoz corporativo.

https://cronicaglobal.elespanol.com/ecoonomia/opinion-ecoonomia/las-claves-de-un-buen-portavoz-corporativo_141503_102. html

Villafañe, Justo (1993). Imagen positiva. Gestión estratégica de la imagen de las empresas. Madrid: Pirámide. ISBN: 84 36807863

Westphalen, Marie-Hélene; Libaert, Thierry (2008). La communication externe de l'entreprise, 2a ed. Paris: Dunod. ISBN: 9782100521388

Zurutuza-Muñoz, Cristina (2014). "Dramatistic theory: A Burkeian approach to the 2004 Madrid terrorist attacks". In: Robert S. Fortner; P. Mark Fackler (eds.). The handbook of media and mass communication theory. USA: Wiley-Blackwell. ISBN: 9780470675052 